\title{
Effect of dietary $\alpha$-tocopheryl acetate on $\alpha$-tocopherol levels in porcine muscle and on lipid oxidation in pork
}

\author{
F. J. Monahan ${ }^{1}$, D. J. Buckley ${ }^{1}$, P. A. Morrissey ${ }^{2}$ and P. B. Lynch ${ }^{3}$ \\ Departments of ${ }^{1}$ Food Technology and ${ }^{2}$ Nutrition, University College, Cork, Ireland \\ ${ }^{3}$ Teagasc, Moorepark Development Centre, Fermoy, Co. Cork, Ireland
}

\section{Introduction}

Lipid oxidation is a major contributor to deterioration in meat quality affecting the flavour, colour, nutritive value and safety of meat and meat products (Gray and Pearson, 1987). $\alpha$-tocopherol functions as an antioxidant in animal tissues by scavenging free radical species which are involved in the initiation and propagation of lipid oxidation (Machlin, 1984). Animal tissue levels of $\alpha$-tocopherol have been shown to be directly related to the logarithm of dietary vitamin E intake (Bieri, 1972; Chow, 1975; Gallo-Torres, 1980). Studies undertaken in the past to investigate the rate of uptake of $\alpha$-tocopherol by various animal tissues (Bieri, 1972; Gutcher, 1988) have shown that plasma and liver $\alpha$-tocopherol levels respond rapidly to changes in dietary $\alpha$-tocopherol while adipose tissue responds slowly. Other tissues have demonstrated an intermediate response. Previous studies in our laboratory have shown that long-term (10 week) and short-term (2 week) pre-slaughter $\alpha$-tocopheryl acetate supplementation of pig diets resulted in a significant increase in plasma and muscle $\alpha$-tocopherol levels in the pig (Monahan, Buckley, Gray, Morrissey, Asghar, Hanrahan and Lynch 1990a; Monahan, Buckley, Morrissey, Lynch and Gray, 1990b). However, the minimum pre-slaughter supplementation time necessary for tissue $\alpha$-tocopherol levels to respond to dietary $\alpha$-tocopherol has not been established. This study had two objectives: (1) to investigate the effect of duration of pre-slaughter supplementation of pig diets with $\alpha$-tocopheryl acetate on $\alpha$-tocopherol levels in porcine tissues including muscle; and (2) to determine the effect of dietary $\alpha$-tocopheryl acetate on lipid oxidation in pork.

\section{Material and methods}

Thirty male Landrace $\times$ Large White pigs weighing about $40 \mathrm{~kg}$ each were randomly divided into five groups of six pigs per group. At the start of the feeding trial all pigs were receiving a standard finisher diet (basal diet) containing $10 \mathrm{mg}$ $\alpha$-tocopheryl acetate per $\mathrm{kg}$ diet. Groups were then allocated to receive an $\alpha$-tocopheryl acetatesupplemented diet containing $200 \mathrm{mg} \alpha$-tocopheryl acetate per $\mathrm{kg}$ diet (Table 1) for 7, 18, 39 and 67 days before slaughtering. The control group was given the basal diet for the duration of the feeding trial. The pigs were housed in an environmentally controlled slatted floor facility at the Pig Husbandry Unit of the Agriculture and Food Development Authority (Teagasc), Moorepark, Fermoy, Co. Cork. The pigs were offered food and water ad libitum. At slaughter, blood samples were collected in $10 \mathrm{ml}$ heparinized tubes and centrifuged $\left(10 \mathrm{~min}, 1500 \mathrm{~g}, 4^{\circ} \mathrm{C}\right)$ within $30 \mathrm{~min}$ of collection. The plasma was separated and stored at $-0^{\circ} \mathrm{C}$. Liver samples, for $\alpha$-tocopherol determination, were taken immediately after slaughter. Following overnight chilling of the carcasses, longissimus dorsi muscle and subcutaneous adipose tissue samples were taken from each carcass. All tissue samples were stored at $-20^{\circ} \mathrm{C}$ until required for analysis ( 2 to 4 weeks).

Plasma and adipose tissue $\alpha$-tocopherol concentrations were determined by the methods of Bieri, Tolliver and Catignani (1979) and Ueda and Igarashi (1987), respectively. Muscle and liver $\alpha$-tocopherol levels were measured by the method of Buttriss and Diplock (1984).

Table 1 Composition of diets

\begin{tabular}{lc}
\hline Ingredient & $(\mathrm{g} / \mathrm{kg}$ diet $)$ \\
\hline Wheat & 709 \\
Soya 48p & 225 \\
Soya oil & 30 \\
Dibasic calcium phosphate & 15 \\
Limestone flour & 11 \\
Salt & 3 \\
Vitamin/mineral mixt & 7 \\
\hline \hline
\end{tabular}

+ Contained $10 \mathrm{mg} \alpha$-tocopheryl acetate per $\mathrm{kg}$ diet in the basal diet and $200 \mathrm{mg} \alpha$-tocopheryl acetate per $\mathrm{kg}$ diet in the supplemented diet. 
(a)

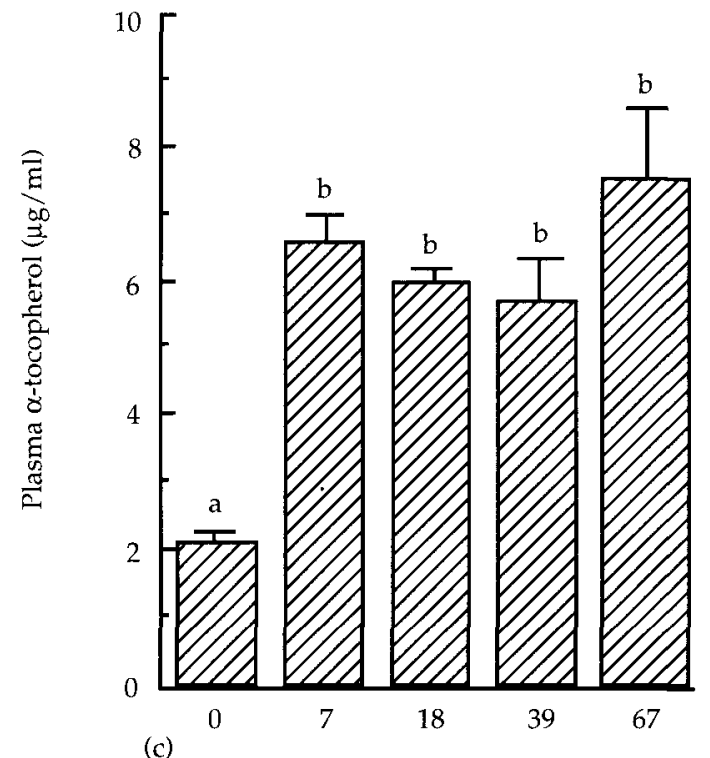

(c) (b)

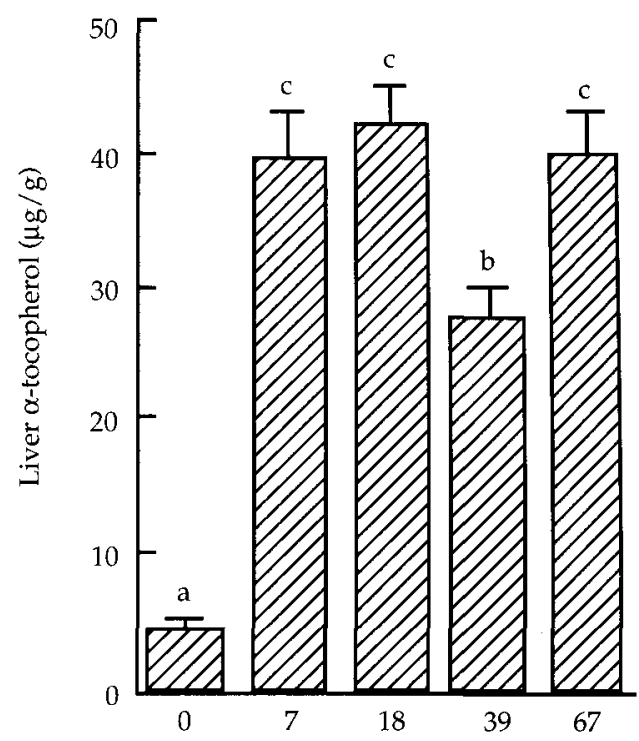

(d)
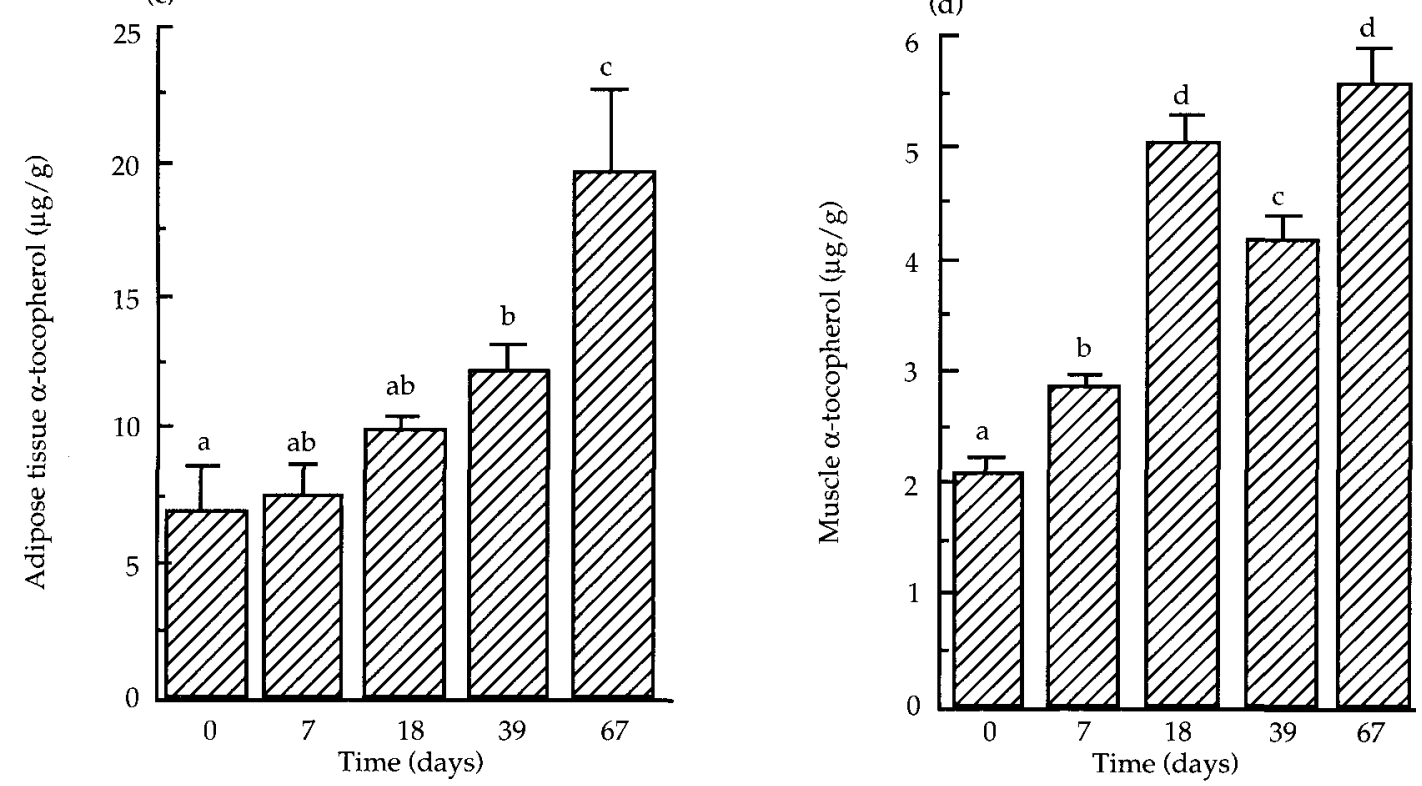

Figure 1 Effect of pre-slaughter dietary $\alpha$-tocopheryl acetate supplementation on $\alpha$-tocopherol levels (mean with s.e.) in (a) porcine plasma, (b) liver, (c) adipose tissue and (d) muscle. Mean values bearing similar letters are not significantly different $(P>0.05)$.

Pork patties (cooked and uncooked) were prepared from muscle samples as described by Monahan et al. (1990a). The extent of lipid oxidation in pork patties during refrigerated storage $\left(4^{\circ} \mathrm{C}\right)$ was assessed by the 2-thiobarbituric acid procedure of $\mathrm{Ke}$, Ackman, Linke and Nash (1977). 2-thiobarbituric acid-reactive substances (TBARS) were expressed as $\mathrm{mg}$ malonaldehyde per $\mathrm{kg}$ sample.
Statistical significance of differences between mean $\alpha$-tocopherol levels and mean TBARS were determined by $t$ test using the Minitab Statistical Package (Ryan, Joiner and Ryan, 1985).

\section{Results}

The effect of pre-slaughter supplementation time on plasma $\alpha$-tocopherol levels is shown in Figure 1(a). 


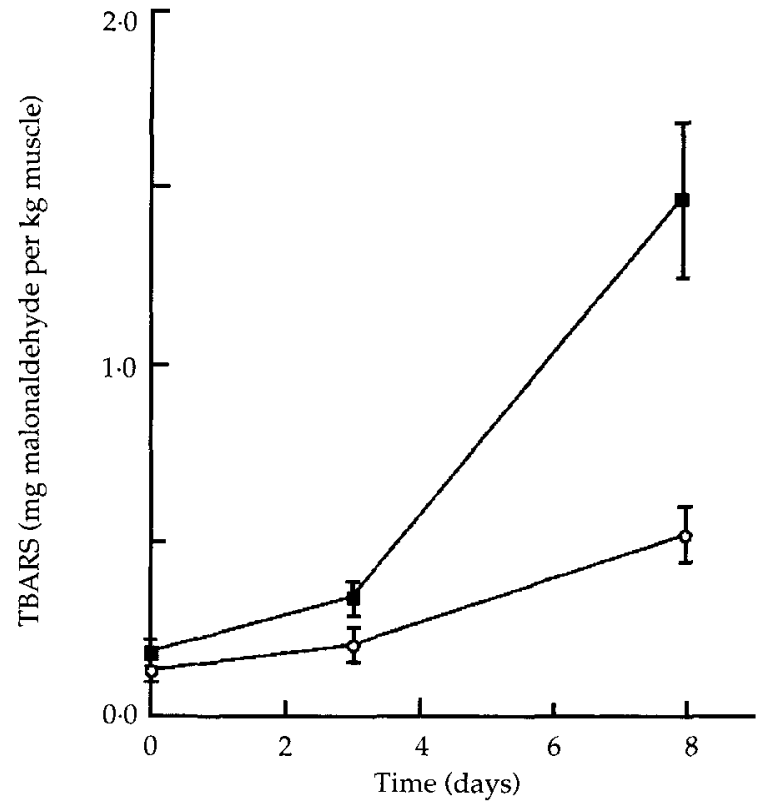

Figure 2 Effect of dietary $\alpha$-tocopheryl acetate on the 2 -thiobarbituric acid-reactive substances (TBARS) values (mean with s.e.) of uncooked pork patties stored at $4^{\circ} \mathrm{C}$ for up to 8 days: $\mathbf{\square}$, control group; $\mathcal{O}$, supplemented group.

Plasma $\alpha$-tocopherol levels of pigs given the supplemented diet for 7 days were 3.0-fold higher than those of pigs given the basal diet. Supplementation for longer than 7 days $(18,39$ or 67 days) did not result in a further significant increase in plasma $\alpha$-tocopherol relative to the 7 -day level. Similarly, in the case of liver $\alpha$-tocopherol, levels had increased significantly compared with the control group after 7 days of supplementation (Figure 1(b)). The $\alpha$-tocopherol content of liver from pigs given the supplemented diet for 7 days was not significantly different from that of pigs given that diet for 18 or 67 days.

In contrast to plasma and liver, adipose tissue $\alpha$-tocopherol responded more slowly to supplementation. Adipose tissue $\alpha$-tocopherol levels were not significantly different from the control group levels after 7 or 18 days of supplementation (Figure 1(c)). After 39 days of supplementation the $\alpha$-tocopherol level of adipose tissue was significantly higher than the control level. Adipose tissue $\alpha$-tocopherol continued to increase up to 67 days of supplementation.

In terms of its responsiveness to pre-slaughter supplementation with $\alpha$-tocopheryl acetate, porcine muscle fell between liver and adipose tissue (Figure 1(d)). Muscle $\alpha$-tocopherol levels were significantly

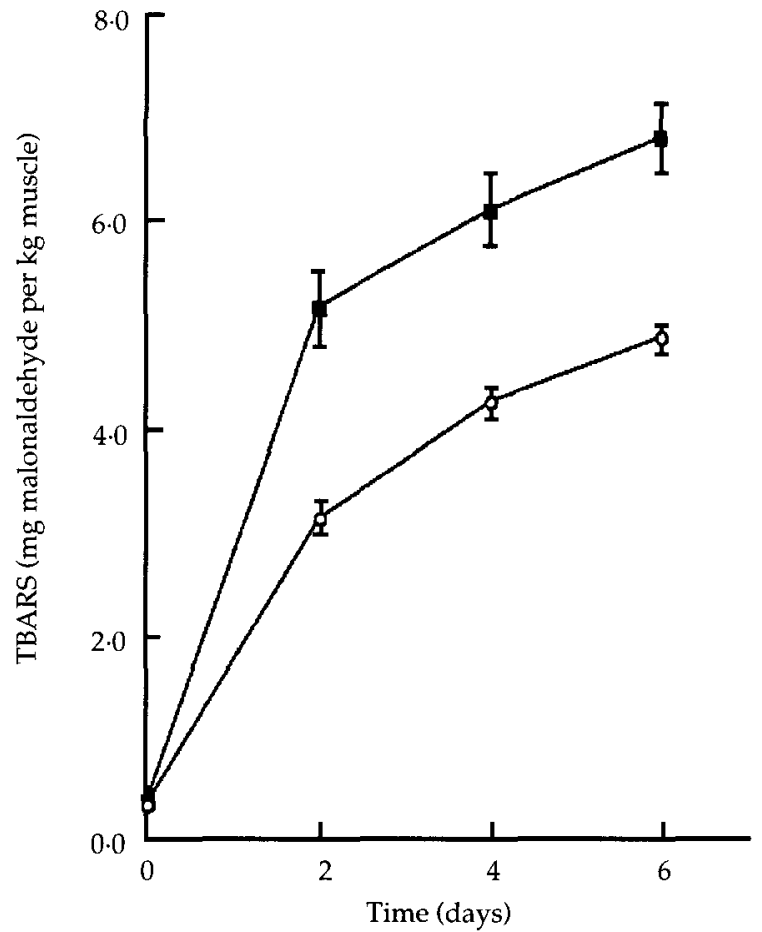

Figure 3 Effect of dietary $\alpha$-tocopheryl acetate on the 2-thiobarbituric acid-reactive substances (TBARS) values (mean with s.e.) of cooked pork patties stored at $4^{\circ} \mathrm{C}$ for up to 4 days: $\square$, control group; $\bigcirc$, supplemented group.

higher after 7 days of supplementation compared with the control group. The 18-day values were significantly higher than the 7-day values. Supplementation for longer than 18 days did not result in any further significant increase in $\alpha$ tocopherol in these tissues.

Cooked and uncooked pork patties from pigs given the supplemented diet for at least 18 days preslaughter were less susceptible to lipid oxidation than pork patties from pigs given the control diet (Figures 2 and 3). Uncooked pork from pigs given the supplemented diet had significantly lower TBARS values than pork from pigs given the control after 8 days of storage $(P<0.05$; Figure 2$)$. The TBARS data also showed that cooked pork from the supplemented group had consistently lower TBARS values than cooked muscle from the control group (Figure 3). Significant differences were observed after $48 \mathrm{~h}$ at $4^{\circ} \mathrm{C}$.

\section{Discussion}

The data presented in Figure 1 illustrate that $\alpha$-tocopherol levels increased with increasing supplementation time from 7 to 67 days in all the 
tissues examined. However, the rate of increase in $\alpha$-tocopherol content, and the supplementation time above which no further significant increase in $\alpha$-tocopherol content was observed, differed from tissue to tissue. In agreement with the present finding, earlier studies with rats (Bieri, 1972; Gutcher, 1988) and guinea pigs (Machlin, Keating, Nelson, Brin, Filipski and Miller, 1979) found plasma and liver to be highly responsive to dietary $\alpha$-tocopherol. Depletion and repletion studies also demonstrated that adipose tissue responded more slowly than other tissues to dietary $\alpha$-tocopheryl (Bieri, 1972; Machlin et al., 1979). In pigs, Jensen, Hakkarainen, Lindholm and Jonsson (1988) reported that porcine liver responded rapidly to dietary $\alpha$-tocopherol acetate intake while muscle and adipose tissue responded at a slower rate.

The results of the present study indicate that a short pre-slaughter supplementation period (18 days) is as effective as long-term supplementation (67 days) in terms of increasing the $\alpha$-tocopherol content of muscle. However, increases in plasma or liver $\alpha$-tocopherol levels may not indicate a corresponding increase in muscle $\alpha$-tocopherol since plasma and tissues respond at different rates to dietary $\alpha$-tocopheryl acetate, particularly in the first 1 to 2 weeks of supplementation.

Cooked and uncooked pork from pigs given the $\alpha$-tocopheryl acetate-enriched diet for 18 days before slaughtering was significantly less susceptible to lipid oxidation than pork from pigs given the basal diet. However, in cooked pork stored for $48 \mathrm{~h}$ or more at $4^{\circ} \mathrm{C}$, the TBARS values of samples from both the control and supplemented groups were above 1.0 , the threshold above which oxidized off-flavours are detectable (Gray and Pearson, 1987). Although the effectiveness of $\alpha$-tocopheryl acetate supplementation in retarding off-flavour development in cooked pork may be modest, dietary supplementation may offer other benefits in terms of improving meat quality. For example, a recent study demonstrated that oxides of cholesterol were significantly lower in cooked pork from pigs given a supplemented diet (200 $\mathrm{mg} \alpha$-tocopheryl acetate per $\mathrm{kg}$ diet) compared with a control group $(10 \mathrm{mg} / \mathrm{kg}$ diet). These lipid oxidation products have been implicated in the aetiology of a number of diseases in humans (Addis and Park, 1989) and some may be of dietary origin (Emanuel, Hassel, Addis, Bergman and Zavoral, 1991).

\section{References}

Addis, P. B. and Park, S. W. 1989. Role of lipid oxidation products in atherosclerosis. In Food toxicology. A perspective on the relative risks (ed. S. L. Taylor and R. A. Scanlan), pp. 297-330. Marcel Dekker, New York.
Bieri, J. G. 1972. Kinetics of tissue $\alpha$-tocopherol depletion and repletion. Annals of the New York Academy of Science 203: 181-191.

Bieri, J. G., Tolliver, T. J. and Catignani, G. L. 1979. Simultaneous determination of $\alpha$-tocopherol and retinol in plasma or red cells by high pressure liquid chromatography. American Journal of Clinical Nutrition 32: 2143-2149.

Buttriss, J. L. and Diplock, A. T. 1984. High-performance liquid chromatography methods for vitamin $\mathrm{E}$ in tissues. Methods in Enzymology 105: 131-138.

Chow, C. K. 1975. Distribution of tocopherols in human plasma and red blood cells. American Journal of Clinical Nutrition 28: 756-760.

Emanuel, H. A., Hassel, C. A., Addis, P. B., Bergman, S. D. and Zavoral, J. H. 1991. Plasma cholesterol oxidation products (oxysterols) in humans fed a meal rich in oxysterols. Journal of Food Science 56: 843-847.

Gallo-Torres, H. E. 1980. Absorption. In Vitamin E. A comprehensive treatise (ed. L. J. Machlin), pp. 170-192. Marcel Dekker, New York.

Gray, J. I. and Pearson, A. M. 1987. Rancidity and warmedover flavor. Advances in Meat Research 3: 221-269.

Gutcher, G. R. 1988. Tissue levels of vitamin E ( $\alpha$-tocopherol) in response to continuous intravenous multivitamin infusion. Journal of Parenteral and Enteral Nutrition 12: 152-154.

Jensen, M., Hakkarainen, J., Lindholm, A. and Jonsson, L. 1988. Vitamin E requirement of growing swine. Journal of Animal Science 66: 3101-3111.

Ke, P. J., Ackman, R. G., Linke, B. H. and Nash D. M. 1977. Differential lipid oxidation in various parts of frozen mackerel. Journal of Food Technology 12: 37-47.

Machlin, L. J. 1984. Vitamin E. In Handbook of vitamins. Nutritional, biochemical and clinical aspects (ed. L. J. Machlin), pp. 99-145. Marcel Dekker, New York.

Machlin, L. J., Keating, J., Nelson, J., Brin, M., Filipski, R. and Miller, O. N. 1979. Availability of adipose tissue tocopherol in the guinea pig. Journal of Nutrition 109: 105-109.

Monahan, F. J., Buckley, D. J., Gray, J. I., Morrissey, P. A., Asghar, A., Hanrahan, T. J. and Lynch, P. B. 1990a. Effect of dietary vitamin $\mathrm{E}$ on the stability of raw and cooked pork. Meat Science 27: 99-108.

Monahan, F. J., Buckley, D. J., Morrissey, P. A., Lynch, P. B. and Gray, J. I. 1990b. Effect of dietary $\alpha$-tocopherol supplementation on $\alpha$-tocopherol levels in porcine tissues and on susceptibility to lipid peroxidation. Food Sciences and Nutrition 42F: 203-212.

Ryan, B. F., Joiner, B. L. and Ryan, T. A. 1985. Minitab handbook. 2nd ed. Duxbury Press, Boston, Massachusetts.

Ueda, T. and Igarashi, D. 1987. New solvent system for extraction of tocopherols from biological specimens for HPLC determination and the evaluation of $2,2,5,7,8$ pentamethyl-6-chromanol as an internal standard. Journal of Micronutrient Analysis 3: 185-198. 